Cite this: Nanoscale, 2014, 6, 5853

Received 4th December 2013 Accepted 11th February 2014

DOI: 10.1039/c3nr06444a

www.rsc.org/nanoscale

\section{Ultrafast and scalable laser liquid synthesis of tin oxide nanotubes and its application in lithium ion batteries $\uparrow$}

\author{
Zhikun Liu, $\neq^{\mathrm{a}}$ Zeyuan Cao, $\sharp^{\mathrm{c}}$ Biwei Deng, ${ }^{a}$ Yuefeng Wang, ${ }^{\mathrm{b}}$ Jiayi Shao, ${ }^{\mathrm{b}}$ \\ Prashant Kumar, ${ }^{a}$ C. Richard Liu, ${ }^{a}$ Bingqing Wei ${ }^{\star c}$ and Gary J. Cheng ${ }^{\star a b}$
}

\begin{abstract}
Laser-induced photo-chemical synthesis of $\mathrm{SnO}_{2}$ nanotubes has been demonstrated by employing a nanoporous polycarbonate membrane as a template. The $\mathrm{SnO}_{2}$ nanotube diameter can be controlled by the nanoporous template while the nanotube length can be tuned by laser parameters and reaction duration. The microstructure characterization of the nanotubes indicates that they consist of mesoporous structures with sub $5 \mathrm{~nm}$ size nanocrystals connected by the twinning structure. The application of $\mathrm{SnO}_{2}$ nanotubes as an anode material in lithium ion batteries has also been explored, and they exhibited high capacity and excellent cyclic stability. The laser based emerging technique for scalable production of crystalline metal oxide nanotubes in a matter of seconds is remarkable. The compliance of the laser based technique with the existing technologies would lead to mass production of novel nanomaterials that would be suitable for several emerging applications.
\end{abstract}

Production of nanomaterials on a large scale and at a fast pace is a current demand as nanotechnology based industries are flourishing and adding new production lines. For better device functionality, one needs to have nanostructures with better spatial uniformity in size, high crystallinity and integration. Most of the presently available techniques employed for the synthesis of nanowires involve multiple steps and are time consuming. Therefore, novel approaches to satisfy the needs of emerging nano-devices are being developed and so is the scalable production of the device components.

Lithium ion batteries ${ }^{1-6}$ are attracting more attention from industry because of their high energy density and compactness. Tin oxide $\left(\mathrm{SnO}_{2}\right)$ nanotubes, as a promising anode material for lithium ion batteries, ${ }^{7-10}$ can be synthesized via either chemical or physical approaches. ${ }^{\mathbf{1 1}-18}$ However, the dimension control, purity and scalability are still issues yet to be addressed. Precision nanomanufacturing of tin oxide nanotubes would therefore be a crucial step towards their energy applications. Lasers are capable of delivering high energy density in an instantaneous manner and have earlier been exploited for the pursuit of material synthesis, ${ }^{\mathbf{1 9}-28}$ which makes them an appropriate and

Industrial Engineering, Purdue University, West Lafayette, Indiana, 47907, USA E-mail: gjcheng@purdue.edu; weib@udel.edu

${ }^{b}$ Birck Nanotechnology Centre, Purdue University, West Lafayette, Indiana, 47907, USA ${ }^{\circ}$ Department of Mechanical Engineering, University of Delaware, Newark, DE, 19716, USA

† Electronic supplementary information (ESI) available. See DOI: 10.1039/c3nr06444a

$\ddagger$ Both authors contributed equally to the paper. suitable choice for on-demand, ultrafast production of nanoarchitectures such as nanowires, nanotubes, nanodots, etc. Laser processing has brought many discoveries and novel approaches in material synthesis with added advantages such as scalability and a fast processing speed.

We hereby demonstrate a laser based approach for the ultrafast photo-chemical synthesis of tin oxide nanotubes by employing a polycarbonate membrane as a template (Fig. 1(a)). It is worth noting that the present technique is not only limited to tin oxide but is also applicable to many materials, and therefore, this emerging flexible technique would pave the way to nanomanufacture nanostructures of many functional material systems. As an example, the electrochemical performance of the $\mathrm{SnO}_{2}$ nanotubes synthesized by the laser based

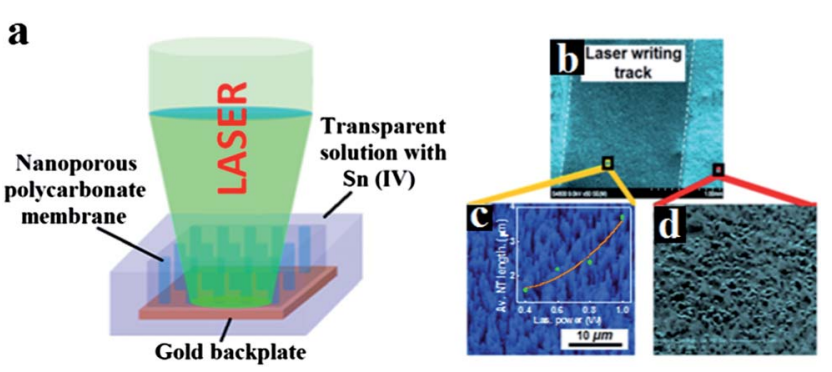

Fig. 1 Schematic of the laser-induced photo-chemical synthesis of $\mathrm{SnO}_{2}$ nanotubes, (b) laser track written on a substrate after the template removal, (c) vertically aligned $\mathrm{SnO}_{2}$ nanotubes inside the laser track (the inset shows laser power dependence of nanotube length) and (d) random features outside the track. 
photochemical technique has also been investigated, and they exhibit an excellent cyclic stability with high rate capability and a high capacity close to the theoretical value.

The lucrative aspect of the present technique is that it provides the freedom to write lines and patterns of vertically aligned nanowires, simply by irradiating the laser along a desired path onto the polycarbonate membrane template. Such a degree of freedom and scalability would be beneficial for patterned nanowire growth which is usually desired for battery devices. Fig. 1(b) shows one of such laser written tracks. Fig. 1(c) and (d) are FESEM images of the microstructures inside and outside the laser written track, respectively. In brief, Fig. 1(c) shows a dense, uniform, and vertically aligned $\mathrm{SnO}_{2}$ nanotube array on the sputtered gold thin film. This image was captured after the polycarbonate nanoporous template was dissolved in the dichloromethane solvent. The height and diameter of the nanotubes are approximately $4 \mu \mathrm{m}$ and $450 \mathrm{~nm}$, respectively. The nanotube diameter can conveniently be controlled by the nanopore's diameter in a polycarbonate nanoporous template. The inset in Fig. 1(c) is a plot of average nanotube length $v s$. laser power. Laser power proves to be a good control parameter for the nanotube length.

Nanotubes fabricated with the present technique have typically thin walls. The TEM image in Fig. 2(a) showing nanotubes with a wall thickness of about $14 \mathrm{~nm}$ confirms this. In order to investigate the nanotube formation and to develop a deeper understanding, we have examined the bottom part of the nanotube formed, which would reveal the early stage of growth features of the nanotubes. The selected area electron diffraction (SAED) pattern from the $\mathrm{SnO}_{2}$ nanotubes exhibits diffraction rings corresponding to [110], [101] and [301] crystallographic planes as shown in Fig. 2(a). Fig. 2(b)-(f) show the details of the $\mathrm{SnO}_{2}$ nanotube formation. As is apparent from the HRTEM image of the bottom of the nanotubes, growth of $\mathrm{SnO}_{2}$ nanotubes begins with ultrafine, $2 \mathrm{~nm}$ diameter $\mathrm{SnO}_{2}$ nanoparticles (see Fig. 2(b)). Fig. 2(c) depicts the formation of mesopores (2-5 $\mathrm{nm}$ in diameter). The image in Fig. 2(d) reveals that the nanoparticles are connected by the twinning structure, which is a typical microstructure at the early stage of nanoparticle coalescence.

When a laser pulse is absorbed by the Au back plate, the irradiated area becomes the heating source for the solution. Since heating at the bottom of the solution generates fluid convection within the channel, the heat transfer of the solution is governed by conduction and convection. Comsol Multiphysics simulation has been carried out which is capable of coupling both heat transfer and laminar flow in solution (conjugate heat transfer mode). Fig. 2(e) is a simulation result showing temperature modulation by a laser pulse at the location $1 \mu \mathrm{m}$ above the back plate within the channel. The temperature gradually rises up to $390 \mathrm{~K}$ within the pulse duration of $400 \mathrm{~ns}$. After the laser pulse is off, the conduction and convection of the fluid cool down the temperature within 200 ns. The cooling rate after the laser pulse is switched off is estimated to be at the scale of $5 \times 10^{8} \mathrm{~K} \mathrm{~s}^{-1}$, which is a very rapid cooling rate.

The synthesis of $\mathrm{SnO}_{2}$ nanotubes in the present technique can easily be understood in terms of laser-induced photochemical decomposition of precursors and consequent crystallization. The heating of the solution leads to stronger ionization of water. The exponential increase of concentration of $\mathrm{OH}^{-}$results in the supersaturation of $\mathrm{Sn}(\mathrm{OH})_{4} \cdot \mathrm{SnO}_{2}$ is then
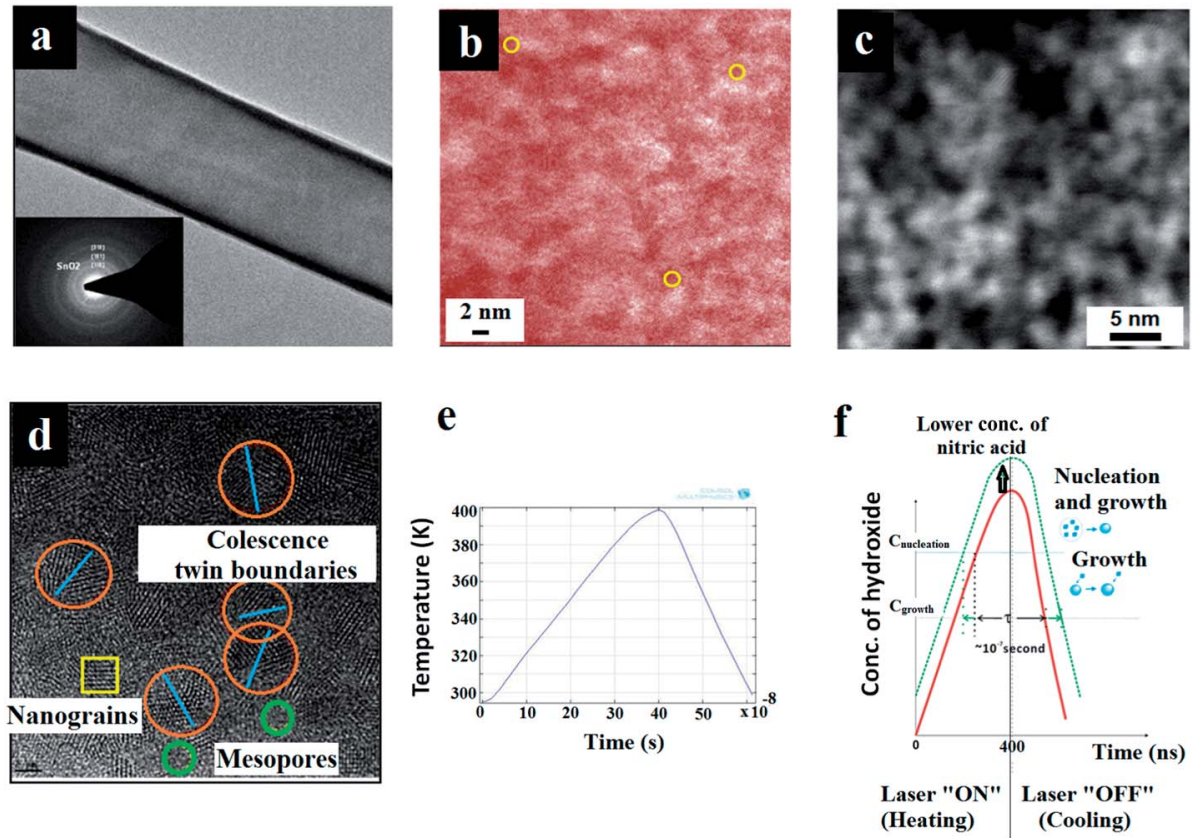

Fig. 2 HRTEM image showing (a) walls of the nanotube formed (the inset shows the selected area electron diffraction pattern), (b) ultrafine $\mathrm{SnO}_{2}$ nanocrystals formed at the gold backplate, (c) mesopores and (d) nanograins, coalescence twin boundaries and mesopores. (e) Simulated thermal profile with the time elapsed and (f) the La Mer model for the crystallization process. 
formed by laser-induced dehydration of $\mathrm{Sn}(\mathrm{OH})_{4}$. The formation of nanocrystalline $\mathrm{SnO}_{2}$ has been confirmed from the diffraction pattern in Fig. 2(a) and the high resolution TEM image in Fig. 2(d).

$$
\begin{gathered}
\mathrm{Sn}^{4+}+4(\mathrm{OH})^{-} \rightarrow \mathrm{Sn}(\mathrm{OH})_{4} \\
\mathrm{Sn}(\mathrm{OH})_{4} \stackrel{\text { laser heating }}{\longrightarrow} \mathrm{SnO}_{2}+2 \mathrm{H}_{2} \mathrm{O}
\end{gathered}
$$

Nucleation and growth occur within a nanosecond time span as the La Mer model ${ }^{29}$ for the laser-induced crystallization in such a photo-chemical reaction, as demonstrated in Fig. 2(f). It is shown in Fig. 2(f) that nucleation can be controlled by the nitric acid concentration. For example, for a solution containing $180 \mathrm{mM}$ nitric acid, fine nanoparticles of $2 \mathrm{~nm}$ diameter formed, while nanoparticles of $3 \mathrm{~nm}$ diameter formed when the nitric acid concentration is reduced to $50 \mathrm{mM}$.

Such laser-induced crystallization of monodispersed ultrafine nanoparticles is very interesting from the crystallization point of view, as the time needed for the crystallization process is only a few hundred nanoseconds. According to La Mer's model, it is necessary to distinguish the nucleation stage and the growth process in timescale in order to achieve a nanocrystal size distribution close to a monodisperse level. As the concentration of hydroxide ions gradually increases above the equilibrium solubility, the nucleation of $\mathrm{Sn}(\mathrm{OH})_{4}$ bursts out when the supersaturation achieves a definite value. Let $C_{\text {nucleation }}$ be the critical concentration of the $\mathrm{OH}^{-}$to trigger nucleation. As soon as the laser is switched off, within a short duration, the nucleation process commences and the temperature quickly drops. At the concentration below $C_{\text {nucleation, }}$, nuclei formation would not be favored. Now, if the duration of nucleation is minimal, monodispersed nanoparticles can be achieved. ${ }^{30}$

After Region II, the crystal growth would proceed until the concentration of growth species has reduced to the equilibrium concentration $C_{\text {growth }}$. Further reduction of the $\mathrm{OH}^{-}$ions into Region IV brings the particle growth to a halt. The duration of time between the commencement of nucleation and the finish point for crystal growth is denoted as $\tau$. The duration $\tau$ of the photochemical process in the present technique is estimated to be at the scale of $10^{-7} \mathrm{~s}$. A smaller $\tau$ value generally favors ultrafine monodispersed nanocrystal growth. In addition, usually the fast cooling rate favors monodispersity in nanoparticle size, even under a wide range of activation energy of crystallization. The cooling rate in the present case of laserinduced photo-chemical transformation is estimated to be at the scale of $5 \times 10^{8} \mathrm{~K} \mathrm{~s}^{-1}$. Also, it should be noted that majority of the laser energy is utilized in photochemical reactions and therefore, residual laser power is not able to give rise to a thermal rise. In addition, an aqueous background does not allow laser pulses to create abnormal thermal spike and helps maintain a low background temperature. This is in contrast to usual laser crystallization techniques where the material undergoes a thermal spike and a moderate cooling rate, which give rise to larger crystals. ${ }^{31}$

Thus, the present photo-chemical technique which yields monodisperse ultrafine nanocrystals relies on the deterministic

factors: (a) adequate concentration of growth species, (b) marginalized $\mathrm{OH}^{-}$ion concentration, (c) low background temperature due to liquid ambient, and (d) supercooling. All of these deterministic factors lead to spontaneous crystal growth with negligible duration and yield monodisperse ultrafine nanocrystals when a particular set of the above factors are created. If the reaction is forced to halt at the moment close to the commencement, one would achieve such monodisperse ultrafine nanocrystals. It has to be noted that the size of the $\mathrm{SnO}_{2}$ nanocrystals achieved in the present work is one of the thinnest nanosized-SnO $\mathrm{O}_{2}$ ever synthesized. From materials point of view, such ultrafine quantum confined semiconducting nanodots (quantum dots) would exhibit fascinating and unusual physical behavior.

The present technique to photo-chemically synthesize inorganic nanotubes, employing a nanoporous cylindrical template, presents a novel approach towards fabrication of nanotubes in a scalable manner. The formation of a tubular structure (see Fig. 3(a)) instead of the solid wire structure can be understood by the fluid convection initiated by bubbling. To study the mechanism of the $\mathrm{SnO}_{2}$ nanotube formation, a control experiment has been carried out by heating the entire solution uniformly at $95{ }^{\circ} \mathrm{C}$ on a hotplate for $10 \mathrm{~min}$. The SEM image shows very short gel-like columns instead of tubes as shown in Fig. 3(c). The inset of Fig. 3(c) is the diffraction pattern of the short columns. The absence of the ring patterns suggests that the column is composed of amorphous $\mathrm{Sn}(\mathrm{OH})_{4}$. Laser induced local heating thus plays two crucial roles in nanotube formation. The first is the laser-induced convection for the formation of the desired tubular structure and the second is the laser dehydration of $\mathrm{Sn}(\mathrm{OH})_{4}$. As discussed earlier, laser local heating
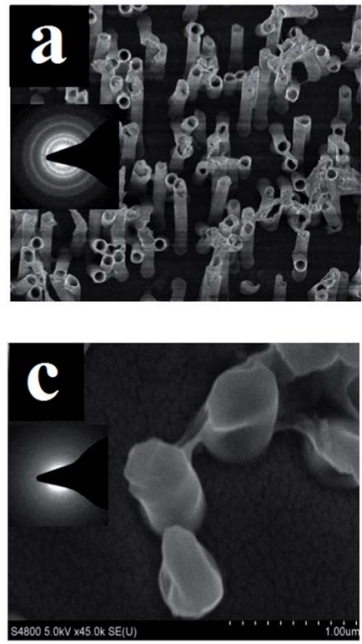

Fig. 3 (a) The top view FESEM image of the tubular structure achieved by laser-induced photo-chemical synthesis (the inset shows the diffraction pattern), (b) the Comsol Multiphysics result of the convection flow during the laser local heating, (c) the top view of the short columnar structure by uniform hot plate heating at $95^{\circ} \mathrm{C}$ and (d) the Comsol Multiphysics result indicating no fluid flow during the hot plate heating. 
generates temperature gradient in the solution. Hotter solution at the bottom of the channel will float up and is replaced by the cold solution. Fluid convection by the buoyancy difference is simulated using the Comsol Multiphysics and shown in Fig. 3(b) and (d). During the laser pulse, the hot fluid flows upward at the center of the channel while the solution is static at the interface to the polycarbonate membrane because of the non slippery boundary conditions. The convection at the center of the channel will prevent the formation of the columnar structure and retain the tubular structure during the growth. The tubular structure formed by laser-induced photo-chemical synthesis is shown in Fig. 3(a). The relative rigid network of the $\mathrm{SnO}_{2}$ nanocrystals prevents the collapse of the thin-wall tubular structures after the polycarbonate template is dissolved. As shown in Fig. 1(b), we have demonstrated that laser can be employed to write patterns consisting of segments, which are constituted by vertically aligned freestanding $\mathrm{SnO}_{2}$ nanotubes. Such patterned features can find incredible importance in device design and manufacturing.

The large surface area inherited from the colloid of $\mathrm{SnO}_{2}$ particles can facilitate the lithium reaction and, therefore, $\mathrm{SnO}_{2}$ nanotubes would act as a nice platform for lithiation. Furthermore, the tubular structures could serve as channels for lithium ion transport to shorten the $\mathrm{Li}^{+}$diffusion length efficiently and to enhance the charge transfer process along the axial direction. To explore the seemingly advantageous electrochemical aspect of the $\mathrm{SnO}_{2}$ nanotubes, electrochemical measurements were performed. Fig. 4(a) presents the galvanostatic dischargecharge profiles of the $\mathrm{SnO}_{2}$ nanotubes at the rate of $0.1 \mathrm{C}$ for the selected cycles: the 1st, 2nd, 10th, 20th, and 100th cycle. The initial capacity of $2750 \mathrm{~mA} \mathrm{~h} \mathrm{~g} \mathrm{~g}^{-1}$ is quite impressive in comparison to the recent literature on lithium ion batteries made up of $\mathrm{SnO}_{2} / \mathrm{Sn}$ systems ${ }^{32}$ and $\mathrm{SnO}_{2}$ nanotubes. ${ }^{33}$ It is also noted from Fig. 4(a) that the capacity sharply drops to $1400 \mathrm{~mA}$ $\mathrm{h} \mathrm{g}^{-1}$, which is only half of the initial capacity after the first discharge. The irreversible loss of capacity is attributed to the formation of the solid electrolyte interface (SEI) and the decomposition of $\mathrm{SnO}_{2}$ to $\mathrm{Sn}$ during the initial cycle. In the beginning the curves retain a similar shape with two distinct short plateaus at around 0.5 and $0.05 \mathrm{~V}$ corresponding to phase transition processes during $\mathrm{Li}^{+}$insertion, which would be clarified in the following cyclic voltammetry (CV) analysis. Whereas, a variation occurs with the cycles: the plateau gradually disappears and the curves become a line with a steepened slope. It is indicative of a typical solid solution reaction by $\mathrm{Li}^{+}$insertion.

The cycling performance of 100 cycles at $0.1 \mathrm{C}$ (Fig. 4(b)) shows that the capacity decreases linearly with a slope of $30 \mathrm{~mA}$ $\mathrm{h} \mathrm{g}^{-1}$ per cycle in the first 20 cycles except initial discharge and evolves in a steady state since the 20th cycle. The capacity retains about $600 \mathrm{~mA} \mathrm{~h} \mathrm{~g}^{-1}$ at the end of the 100th cycle while it was $818 \mathrm{~mA} \mathrm{~h} \mathrm{~g}^{-1}$ at the 20th cycle. The capacity degradation rate is about $2.75 \mathrm{~mA} \mathrm{~h} \mathrm{\textrm {g } ^ { - 1 }}$ per cycle during the last eighty cycles. It is evident that the capacity and cyclic stability are improved exceptionally well as compared with the commercial $\mathrm{SnO}_{2}$ nanopowders that usually fade quickly within 50 cycles. The electrochemical impedance spectra (EIS) in Fig. S1 (ESI) $\dagger$ for the four respective cycles (1st, 5th, 25th and 100th cycle) also show similar Nyquist plots comprised of a depressed semicircle at a high frequency attributed to the charge-transfer process at the electrolyte/electrode interface and a linear tail named the Warburg component at low frequencies corresponding to the $\mathrm{Li}^{+}$diffusion in the solid electrodes. Their knee frequency (intersection between the semicircle and Warburg tail) is at around $15 \mathrm{~Hz}$ close to each other and the similar charge- a

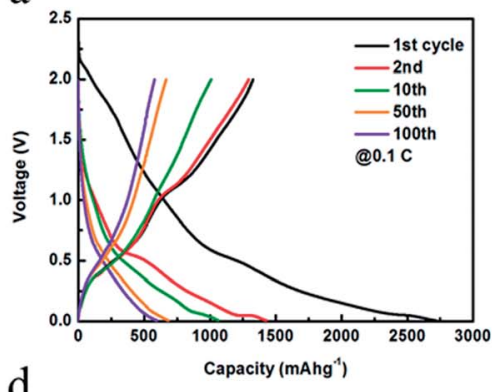

d

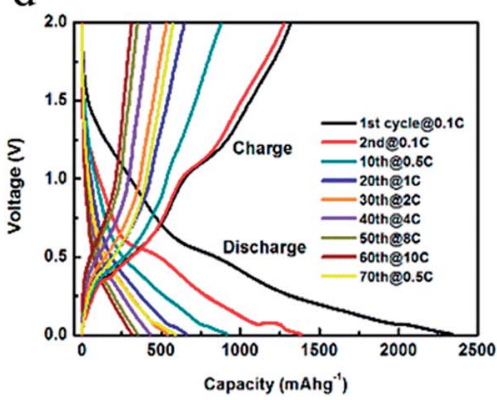

b

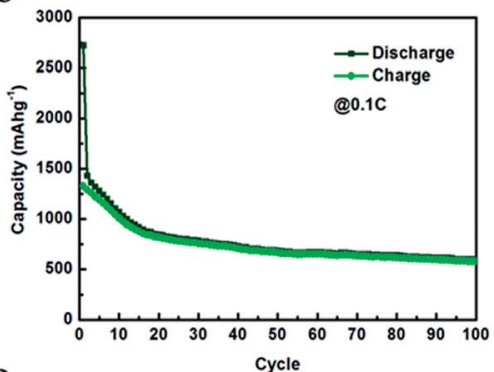

e

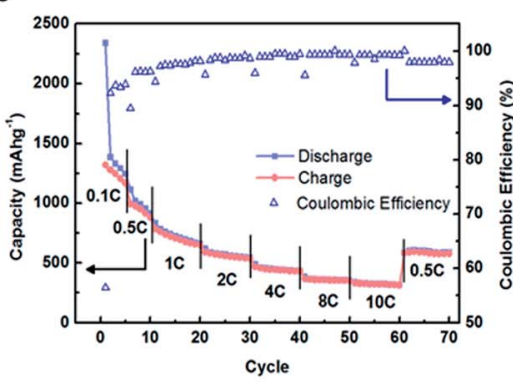

c

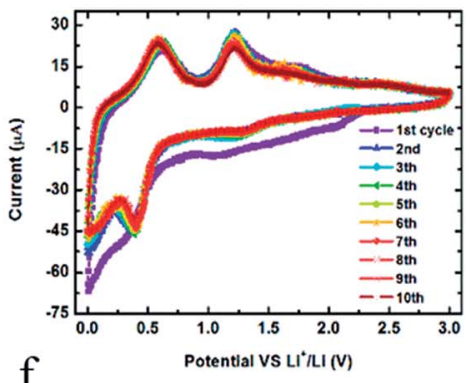

$\mathrm{f}$

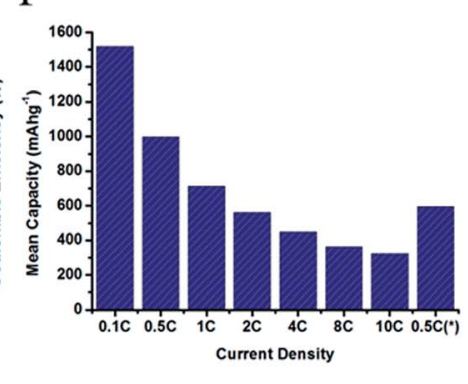

Fig. 4 (a) The discharge-charge profiles for $\mathrm{SnO}_{2}$ nanotubes at different rates; (b) the capacity retention and Coulombic efficiency of SnO nanotubes at various discharge-charge rates, (c) the histogram of the mean capacity at specific rates for the corresponding cycles in (b); and (d) the CV curves at selected cycles. 
transfer resistances deduced from the radius of the semicircle reveal similar kinetics.

The CV curves in consecutive ten cycles are presented in Fig. 4(c). There are two well-defined cathodic peaks at around $0.05 \mathrm{~V}$ and $0.5 \mathrm{~V}$ for all the curves except for a broad peak in the range of $0.5-2 \mathrm{~V}$ during the first cycle, which comes from the reduction of $\mathrm{SnO}_{2}$ by $\mathrm{Li}^{+}$to $\mathrm{Sn}$ and formation of $\mathrm{Li}_{2} \mathrm{O}$ in eqn (3). This reaction accounts for the irreversible loss of capacity shown in Fig. 4(b). The peaks at $0.5 \mathrm{~V}$ and $0.05 \mathrm{~V}$ correspond to the formation of a series of $\mathrm{Li}-\mathrm{Sn}$ alloys, $\mathrm{Li}_{x} \mathrm{Sn}$ as described in eqn (4).

$$
\begin{gathered}
\mathrm{SnO}_{2}+4 \mathrm{Li}^{+}+4 \mathrm{e}^{-} \rightarrow \mathrm{Sn}+2 \mathrm{Li}_{2} \mathrm{O} \\
\mathrm{Sn}+x \mathrm{Li}^{+}+x \mathrm{e}^{-} \leftrightarrow \mathrm{Li}_{x} \mathrm{Sn}(0 \leq x \leq 4.4)
\end{gathered}
$$

In the anodic sweep, the two peaks at $0.55 \mathrm{~V}$ and $1.25 \mathrm{~V}$ are ascribed to the reversed dealloying processes of eqn (4) mainly in two steps. All the four features related to the lithium insertion/extraction in eqn (4) are well overlapped with cycles, indicating the excellent reversible capacity of lithiation. This is in good agreement with the previous results of capacity retention.

We also evaluated the electrochemical performance of the $\mathrm{SnO}_{2}$ nanotubes in terms of rate capability by means of galvanostatic discharge-charge cycling tests at a variety of high rates up to $10 \mathrm{C}$. The discharge-charge curves (Fig. 4(d)) show that the tendency of variation with cycles becoming a smooth slope is facilitated under the large current densities. Neither plateaus nor inflection on the curve could be observed after the 40th cycle at 4 C. The overall cycling performance at different rates (figure (e)) has a similar trend as was found for the experiment at a constant rate of $0.1 \mathrm{C}$. When raising the minimum rate of $0.1 \mathrm{C}$ to the maximum $10 \mathrm{C}$ and back to $0.5 \mathrm{C}$, the corresponding Coulombic efficiency varies from $93 \%$ to $99 \%$ and returns back to $98 \%$.

The histogram (Fig. 4(f)) visually exhibits the comparison of the average capacity at various rates. The mean value of the capacities in the first five cycles at $0.1 \mathrm{C}$ is $1500 \mathrm{~mA} \mathrm{~h} \mathrm{~g}^{-1}$ which is the highest of all. The values for $0.5 \mathrm{C}, 1 \mathrm{C}, 2 \mathrm{C}, 4 \mathrm{C}, 8 \mathrm{C}$ and $10 \mathrm{C}$ were observed to be $998 \mathrm{~mA} \mathrm{~h} \mathrm{~g}^{-1}, 715 \mathrm{~mA} \mathrm{~h} \mathrm{~g}^{-1}, 560 \mathrm{~mA} \mathrm{~h}$ $\mathrm{g}^{-1}, 448 \mathrm{~mA} \mathrm{~h} \mathrm{~g}^{-1}, 361 \mathrm{~mA} \mathrm{~h} \mathrm{~g}{ }^{-1}$, and $324 \mathrm{~mA} \mathrm{~h} \mathrm{~g}^{-1}$, respectively. The capacity of $324 \mathrm{~mA} \mathrm{~h} \mathrm{~g}^{-1}$ at $10 \mathrm{C}$, which was performed within $6 \mathrm{~min}$. is an encouraging result. In the last 10 cycles back to the low rate of $0.5 \mathrm{C}$, the capacity recovers to about $600 \mathrm{~mA} \mathrm{~h} \mathrm{~g}^{-1}$ on average, further confirming the excellent cyclic stability of the $\mathrm{SnO}_{2}$ nanotubes.

Since the structural integrity throughout the cycling tests ensures the good cyclability, the morphology variation of the $\mathrm{SnO}_{2}$ nanotube electrodes over continuous discharge-charge cycles at $0.1 \mathrm{C}$ has been studied by means of SEM. Although the nanotubes experience deformation obviously with enlarged sizes and curled edges, only a small bunch of tubes are fully collapsed as marked in Fig. S2(a); $\uparrow$ and tubes are rarely found cracked (Fig. S2(b)†). Many initially isolated and vertically standing $\mathrm{SnO}_{2}$ nanotubes are aggregated to bundles by the SEI layers wrapped along the tube walls as highlighted in Fig. S2(d). $\dagger$ From the top view of the nanotubes (Fig. S2(c) and (e)), $\dagger$ it is easy to find that the ultrafine nanoparticles are still intact together to constitute the tube walls after cycling. The hollow tubes are filled with the Li-Sn alloy during lithium insertion, which could be seen from the interior of the nanotubes cracked along the generating line of the cylinder in Fig. S2(f) $\cdot \dagger$

In summary, the laser-induced photo-chemical technique to synthesize $\mathrm{SnO}_{2}$ nanotubes has been demonstrated. The diameter of the nanotubes can be tuned with nanoporous template dimensions and the length of the nanotube can be controlled by laser pulse irradiation duration and laser power. The growth of $\mathrm{SnO}_{2}$ nanotubes is catalyzed by laser heated hot zones on a gold back plate. Laser triggered photo-chemical reactions of precursors in an aqueous environment, which yields fast cooling and results in the formation of ultrafine $\mathrm{SnO}_{2}$ nanocrystals. These ultrafine $\mathrm{SnO}_{2}$ nanocrystals assemble themselves in rings and thus in turn nanotubes are built up by vertical alignment of such ultrafine nanocrystals. Heat convection plays an important role by creating favorable experimental conditions. This emerging photo-chemical synthesis of nanotubes can conveniently be generalized to other material systems and nanostructures. The patterning capability of such a laserbased photochemical fabrication technique has also been demonstrated. Instantaneous synthesis of inorganic nanotubes in a scalable manner with the achievement of high quality material crystallinity makes this novel technique very unique. Lithium ion batteries were fabricated using the $\mathrm{SnO}_{2}$ nanotubes synthesized by this emerging technique and electrochemical performance was observed to be better than other $\mathrm{SnO}_{2}$ based nanosystems.

\section{Experimental section}

A focused laser beam (Q-switch long-pulse Nd-YAG fiber laser of wavelength $532 \mathrm{~nm}$ and pulse width $200 \mathrm{~ns}$ ) of size $1 \mathrm{~mm}$ has been irradiated on a transparent solution $\left(25 \mathrm{mM} \mathrm{SnCl}_{4}\right.$ and 180 $\mathrm{mM} \mathrm{HNO}_{3}$ ) lying above a nanoporous membrane [a polycarbonate nanoporous template with a $400 \mathrm{~nm}$ pore size (Whatman ${ }^{\circledR}$ polycarbonate membrane filter, $7 \mu \mathrm{m}$ thick)], which was back-coated by a $50 \mathrm{~nm}$ gold thin film. The experimental set-up for the present approach is shown in Fig. 1(a). The gold thin film absorbs the laser energy, heats up a certain amount of chemical solution and thereby initiates the chemical reaction needed for the growth of the $\mathrm{SnO}_{2}$ nanotubes. The laser can cover millions of nanopores in a single scan. When the growth of nanotubes finished, a $1 \mu \mathrm{m}$ thick layer of copper was electrodeposited on the top of the Au thin film to provide the required mechanical support. The polycarbonate nanoporous template is then dissolved in dichloroethane and vertically aligned $\mathrm{SnO}_{2}$ nanotubes are obtained. Field emission scanning electron microscopy (FESEM) and transmission electron microscopy (TEM) were employed for characterizing the nanoshapes formed. Comsol Multiphysics simulation has been carried out to investigate and understand the nanotube growth process. To be specific, two different simulations have been performed namely, (a) thermal profiling of the photo-chemical process in time scale, which has yielded $\mathrm{SnO}_{2}$ nanotubes and (b) convection of heat inside the interior space in the nanoporous template, with and without flow. The electrochemical 
measurements were performed in a coin cell configuration consisting of the as-prepared $\mathrm{SnO}_{2}$ nanotubes without any posttreatment as the working electrode and metallic $\mathrm{Li}$ as the counter and reference electrode. Celgard 2500 were chosen as separators and $1 \mathrm{M} \mathrm{LiPF}$ dissolved in $1: 1 \mathrm{v} / \mathrm{v}$ ethylene carbonate (EC) : diethyl carbonate (DEC) was used as the electrolyte obtained from Ferro Co. Cyclic voltammetry (CV) measurements and electrochemical impedance spectra (EIS) were collected by using a PARSTAT 2273 (Princeton Applied Research) potentiostat/galvanostat. CV was carried out at a scan rate of $0.1 \mathrm{mV} \mathrm{s}^{-1}$ in the potential window of $0-3 \mathrm{~V}$ to identify the electrochemical reactions with lithium during cycling. EIS was performed with a $10 \mathrm{mV}$ AC signal from $100 \mathrm{kHz}$ to $10 \mathrm{mHz}$. The galvanostatic discharge-charge tests were carried out using BT-4 4-channel battery test equipment (Arbin Instrument, Ltd.).

\section{Acknowledgements}

Authors would like to acknowledge financial support from the Purdue Office of Vice President for Research. BQW gratefully acknowledges the financial support from the US National Science Foundation (NSF) under the contract of 1067947.

\section{References}

1 J.-M. Tarascon and M. Armand, Nature, 2001, 414, 359-367.

2 A. S. Aricò, P. Bruce, B. Scrosati, J.-M. Tarascon and W. V. Schalkwijk, Nat. Mater., 2005, 4, 366-377.

3 B. Scrosati, Electrochim. Acta, 2000, 45, 2461-2466.

4 N. Li, C. R. Martin and B. Scrosati, J. Power Sources, 2001, 97, 240-243.

5 P. Poizot, S. Laruelle, S. Grugeon, L. Dupont and J.-M. Tarascon, Nature, 2000, 407, 496-499.

6 B. Scrosati, J. Hassoun and Y.-K. Sun, Energy Environ. Sci., 2011, 4, 3287-3295.

7 Y. Idota, T. Kubota, A. Matsufuji, Y. Maekawa and T. Miyasaka, Science, 1997, 276, 1395-1397.

8 F. Belliard, P. A. Connor and J. T. S. Irvine, Solid State Ionics, 2000, 135, 163-167.

9 J. Y. Huang, L. Zhong, C. M. Wang, J. P. Sullivan, W. Xu, L. Q. Zhang, S. X. Mao, N. S. Hudak, X. H. Liu, A. Subramanian, H. Fan, L. Qi, A. Kushima and J. Li, Science, 2010, 330, 1515-1520.

10 M.-S. Park, G.-X. Wang, Y.-M. Kang, D. Wexler, S.-X. Dou and H.-K. Liu, Angew. Chem., Int. Ed., 2007, 119, 764-767.

11 Y. Wang, X. Jiang and Y. Xia, J. Am. Chem. Soc., 2003, 125, 16176-16177.
12 P. Meduri, C. Pendyala, V. Kumar, G. U. Sumanasekera and M. K. Sunkara, Nano Lett., 2009, 9, 612-616.

13 J. Q. Hu, X. L. Ma, N. G. Shang, Z. Y. Xie, N. B. Wong, C. S. Lee and S. T. Lee, J. Phys. Chem. B, 2002, 106, 3823-3826.

14 Z. R. Dai, J. L. Gole, J. D. Stout and Z. L. Wang, J. Phys. Chem. $B, 2002,106,1274-1279$.

15 X. Jiang, Y. Wang, T. Herricks and Y. Xia, J. Mater. Chem., 2004, 14, 695-703.

16 S. Luo, J. Fan, W. Liu, M. Zhang, Z. Song, C. Lin, X. Wu and P. K. Chu, Nanotechnology, 2006, 17, 1695-1699.

17 P. Parthangal, R. E. Cavicchi, D. C. Meier, A. Herzing and M. R. Zachariah, J. Mater. Res., 2011, 26, 430-436.

18 G. Sberveglieri, I. Concina, E. Comini, M. Falasconi, M. Ferroni and V. Sberveglieri, Vacuum, 2012, 6, 532-535.

19 A. M. Morales and C. M. Lieber, Science, 1998, 279, 208-211. 20 D. H. Lowndes, D. B. Geohegan, A. A. Puretzky, D. P. Norton and C. M. Rouleau, Science, 1996, 273, 898-903.

21 A. E. Espinal, L. Zhang, C.-H. Chen, A. Morey, Y. Nie, L. Espinal, B. O. Wells, R. Joesten, M. Aindow and S. L. Suib, Nat. Mater., 2010, 9, 54-59.

22 Z. Liu, D. Zhang, S. Han, C. Li, T. Tang, W. Jin, X. Liu, B. Lei and C. Zhou, Adv. Mater., 2003, 15, 1754-1757.

23 V. V. Osipov, Y. A. Kotov, M. G. Ivanov, O. M. Samatov, V. V. Lisenkov, V. V. Platonov, A. M. Murzakaev, A. I. Medvedev and E. I. Azarkevich, Laser Phys., 2006, 16, 116-125.

24 F. Kim, J. H. Song and P. Yang, J. Am. Chem. Soc., 2002, 124, 14316-14317.

25 M. Sakamoto, M. Fujistuka and T. Majima, J. Photochem. Photobiol., C, 2009, 10, 33-56.

26 V. S. Letokhov, Appl. Phys. B, 1988, 46, 237-251.

27 P. Kumar, RSC Adv., 2013, 3, 11987-12002.

28 S. Besner and M. Meunier, Laser Synthesis of Nanomaterials, in Laser Precision Microfabrication, ed. K. Sugioka, et al., Springer, Series in Materials Science, 135, DOI: 10.1007/ 978-3-642-10523-4_7, 2010.

29 V. K. LaMer, J. Am. Chem. Soc., 1950, 72, 4847-4854.

30 G. Cao, in Nanostructures and Nanomaterials, Synthesis, Properties and Applications, Imperial College Press, London, 2004, p. 53, ISBN 1-86094-480-9.

31 P. Kumar and M. G. Krishna, Phys. Status Solidi A, 2009, 207, 947-954.

32 K. Kravchyk, L. Protesescu, M. I. Bodnarchuk, F. Krumeich, M. Yarema, M. Walter, C. Guntlin and M. V. Kovalenko, J. Am. Chem. Soc., 2013, 135, 4199-4202.

33 J. Ye, H. Zhang, R. Yang, X. Li and L. Qi, Small, 2010, 6, 296306. 